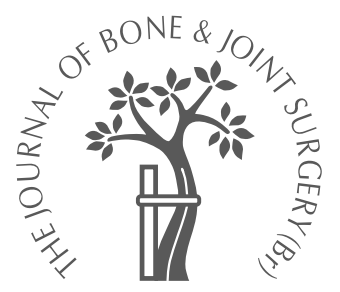

C. B. D. Lavy, N. Mkandawire, W. J. Harrison

From the University of Malawi, Blantyre, Malawi

C. B. D. Lavy, Professor N. Mkandawire, Senior Lecturer, Head of

Department

W. J. Harrison, Consultant, Training Supervisor Department of Orthopaedic Surgery, College of Medicine, University of Malawi, Private Bag 360, Blantyre 3, Malawi.

Correspondence should be sent to Professor C. B. D.

Lavy at Beit Trust Cure International Hospital, P. O. Box 31236, Blantyre 3, Malawi.

(C)2005 British Editorial Society of Bone and Joint Surgery doi:10.1302/0301-620X.87B1. $15713 \$ 2.00$

$J$ Bone Joint Surg [Br] 2005;87-B:10-11.

- ANNOTATION

\title{
Orthopaedic training in developing countries
}

More than $80 \%$ of the population of the world and a vast reservoir of orthopaedic pathology is located in developing countries. Our experience is mainly in central and sub-Saharan Africa, yet our conclusions hold for poor countries of all continents.

\section{Need}

The need for both elective and emergency orthopaedic services in developing countries is great. Most of the degenerative musculoskeletal diseases seen in the West are prevalent, as well as conditions such as untreated club foot, gross genu varum and valgus, tuberculosis of the spine and severe chronic osteomyelitis. Road traffic accidents are becoming an epidemic. More than $80 \%$ of deaths in road traffic accidents and more than $90 \%$ of those involving children occur in developing countries. ${ }^{1}$ In Malawi there are only four orthopaedic surgeons to care for a population of 12 million people. The need for postgraduate training in orthopaedic surgery in a developing country is undeniable, but whether this should be the only level of training depends on the general level of health services in the country. In Malawi, most of the 25 district hospitals have only one doctor of Senior House Officer level and no specialists. The majority of patients are managed by paramedical personnel known as clinical officers. Our main emphasis in training is to instruct these clinical officers in practical orthopaedics and the treatment of fractures. Each district hospital has one or more orthopaedic clinical officers (OCOs), who are able to treat most trauma safely and relatively conservatively. We have a visiting consultant support service which is patchy at present, but will improve as the number of trained specialists increases. Thus, in Malawi a two-tiered orthopaedic training programme has evolved, where we can train OCOs and postgraduate orthopaedic surgeons side-by-side. The majority of the OCOs work at the district level, while the orthopaedic surgeons are in central or teaching hospitals pro- viding service for clinical referral and increasing the scope of training programmes. We believe this is to be a realistic, cost-effective, and achievable strategy. Other developing countries, where there are more doctors, may aim to have a postgraduate level surgeon at every district hospital (either an orthopaedic surgeon, or a generalist with orthopaedic experience).

\section{Training}

A developing country has three options available to train its orthopaedic surgeons. It can try to carry out all the training within its own borders. For the bigger countries with established medical structures, such as Nigeria and Uganda, this is feasible. They have well-run postgraduate programmes in orthopaedic surgery. In smaller countries with less developed services where there are very few qualified trainers, the breadth of training is severely limited, even though the spectrum of disease may be wide.

The second option aims to address the problem with a regional rather than a national approach. In our region we have recently set up a training scheme under the newly formed College of Surgeons of East Central and Southern Africa (COSECSA). ${ }^{2}$ This allows trainees to augment the teaching available in their own country and to work under approved trainers in other countries in the region. COSECSA organises a membership examination in basic surgical sciences and an exit level fellowship in orthopaedics. However, the existence of a training scheme and an examination system does not mean that residents automatically receive good training. Two other components are needed, namely good hospital conditions and keen trainers. These are not always available together in government or university hospitals, and in Malawi we have encouraged cooperation with private and mission hospitals in order to benefit from their facilities and expertise. With such cooperation the trainee gets the best that the country can offer. In other countries 
the private sector is not always amenable to participate in training, and where private patients are limited there may even be opposition or obstruction to training programmes.

The third option is to send trainees to more developed countries for all of their instruction. Historically, this was the only option for many. It will always remain a possibility, and although the training is usually of a high standard there are several disadvantages. The pathology in more developed countries is very different and few trainees who do all their postgraduate training in developed countries ever return. We believe that there are benefits to a short period in a developed country, probably at the end of the national or regional training. This should be for approximately one year and concentrate on a particular aspect such as joint replacement or spinal surgery. Where possible such visits should be arranged as a formal exchange between trainees from developed and developing countries. The benefits of a visit at this stage in training are many and include exposure to modern technology, a different medical culture and the forging of academic and professional links and friendships, many of which will last a lifetime. These links facilitate orthopaedic education in its broadest sense, allowing the exchange of ideas to continue long after the formal period of training is over.

\section{After training}

Trained orthopaedic surgeons are desperately needed in developing countries but their provision in a poor country often highlights other needs. Modern orthopaedics is expensive, and a surgeon trained to the highest theoretical and practical level in internal fixation of fractures can become frustrated working in a country where a simple small fragment plate and six screws costs more than the annual health budget for ten people. The surgeon will have to struggle with out-of-date or broken equipment, theatres of less than perfect cleanliness and staffing levels which are so low that nurses may not even meet all the patients, let alone nurse them. This encourages the use of less costly conservative methods of treatment. Often these are appropriate, but sometimes they are second best, and it is a struggle not to compromise the quality of care. Salaries paid by governments to specialists in developing countries are often insufficient to keep a family fed, let alone cover school fees or buy a car. Many orthopaedic surgeons have to undertake private practice just to survive. Continuing medical education is seldom mandatory in developing countries and even if the surgeon is keen to keep up-to-date, this is not easy, as colleagues may not be like-minded; journals are few and the internet, if available, is usually very slow. We are fortunate in our region of Africa as COSECSA tries to address the need of continuing medical education, but conferences usually involve travel to one of the other countries in the region which is time-consuming and costly. If trained orthopaedic surgeons are to stay and work in their countries, efforts to improve the conditions of work, remuneration, and incentives to stay must be a priority for national governments.

\section{The challenge to developed countries}

The orthopaedic needs of people in developing countries are immense and the plight of our orthopaedic colleagues both trained and in training is precarious. It is useful to compare our lot with that of our colleagues in developing countries. How may concerned orthopaedic surgeons best help? Some will want to visit, and we have benefited greatly from open-minded orthopaedic visitors, bringing both expertise and equipment. A recent hip course sponsored by the Royal College of Surgeons and industry has enabled us to begin a joint replacement service. Programmes of volunteer visiting surgeons can greatly strengthen local postgraduate training programmes. Secondment of trainees from programmes in the United Kingdom allow them to visit developing countries, bringing many mutual benefits. Such a visit allows trainees to expand their minds and catch a glimpse of the orthopaedic problems of the underdeveloped world. They see the natural history and results of untreated pathology. Surgeons who manage club feet may never have seen teenagers or adults with severe untreated feet walking on the head of the talus and the lateral malleoli. Few have seen a sequestrum involving most of the tibia or patients who have walked for months on untreated displaced fractures of the ankle. Visits from trainees also forge friendships and mutual respect for colleagues in different parts of the world. Most who have visited our unit have also been involved in mutually beneficial research projects. Heads of training programmes in the United Kingdom may find appropriate spaces for trainees from developing countries who wish to acquire particular skills.

Material support in the form of donated orthopaedic equipment can go a long way toward improving the training environment of residents in the developing world. As well as equipment, the donation of 'knowledge', by, for instance, subscriptions to international journals can be invaluable. The internet has opened up access to electronic information for trainees in developing countries, but there is still the need for equipment and continued financial support to make it available.

The orthopaedic world is becoming smaller and closer. When the senior author (CBDL) made arrangements to visit Malawi in 1994, it was by aerogramme as the internet had not yet been established in Malawi, and phone lines were unreliable. Now that communication is almost instantaneous, it is our hope that orthopaedic training in the developing countries will be a concern for us all, that training programmes in the developed world will ask what they can do on a global level, and that communications, visits in both directions, bilateral research programmes and mutual understanding will continue to bring us closer together.

\section{References}

1. Nantulya VM, Reich MR. The neglected epidemic: road traffic injuries in developing countries. BMJ 2002;324:1139-41.

2. Lavy CBD. New college of surgeons in Africa. Surgeons' News: Royal College of Surgeons of Edinburgh, 2002;1:74. 